\title{
Improving Financial Service Delivery to Communities through Micro-finance Institutions in Uganda; the case of Pride Micro- finance Limited (PML)
}

\author{
Joseph Wamema $^{1}$ and Joseph Othieno ${ }^{2}$
}

(C) Uganda Martyrs University

\begin{abstract}
This study examined the design of a target Enterprise Architecture (EA) that can enable Micro-finance Institutions (MFIs) in Uganda improve financial service delivery to communities through use of Information and Communication Technologies (ICTs). Pride Micro-finance Limited (PML) was investigated with specific focus on their mission and goals, business processes, information/data, applications, actors, and technological infrastructure. Data was collected from two branches of PML using questionnaires, observation and document reviews. This data was analysed qualitatively and the results of the analysis indicated that PML faces a number of challenges in financial service delivery; like inability to reach out to its customers in a cost effective manner, inefficient ways of processing customer information, and data/information security risks. Based on findings from this study, a target EA capable of enabling PML reach out to its customers in a more sustainable, efficient, and effective manner was designed and recommendations for its implementation made.
\end{abstract}

Key words $\cdot$ Enterprise architecture $\cdot$ Information and communication technologies $\cdot$ Financial service delivery

L'amélioration de la prestation des services financiers aux communautés par le biais des institutions de micro-finance en Ouganda: le cas de Pride Micro-finance Limited (PML)

Résumé. Cette étude s'agit de la conception d'une architecture d'entreprise (AE) cible qui peut permettre aux institutions de micro-finance (IMF) en Ouganda d'améliorer la prestation de services financiers aux communautés grâce à l'usage des technologies de l'information et de la communication (TIC). Pride Micro-finance Limited (PML) a été étudiée avec attention spéciale portée sur leur mission et leurs objectifs, les processus d'affaires, l'information/données, des applications, des acteurs, ainsi que leur infrastructure technologique. Les données ont été recueillies à partir de deux branches de PML par utilisation de questionnaires, l'observation et l'examen de documents. Ces données ont été l'objet d'une analyse qualitative et les résultats de l'analyse ont indiqué que PML est confrontée à un certain nombre de défis dans la prestation de services financiers, comme l'incapacité à se rapprocher de ses clients de manière rentable, l'inefficacité des moyens de traitement des informations du client, et de données/information portant sur des risques de sécurité. En se fondant sur les résultats de cette étude, une AE cible capable de permettre PML de tendre la main à ses clients d'une manière plus durable, efficiente, et efficace a été conçue et des recommandations pour sa mise en cuvre dégageés.

Mots clés: Architecture d'entreprise - les technologies de l'information et de la communication - la prestation de services financiers

\section{Introduction}

1 A member of the National Task force for the Government of Uganda Enterprise Architecture Project and a part-time lecturer at Uganda Martyrs University teaching Enterprise Architecture

2 An Information Technology Consultant and Lecturer at University of Kisubi - Entebbe Uganda 
World over, there has been a remarkable significance in the use of Information and Communication Technologies(ICTs) in facilitating business processes as a way of enhancing efficiency and productivity in service delivery. In fact, it is said that presently without the use of ICTs, a business cannot be sustainable and competitive (Mulira, 2006). Micro-finance Institutions (MFIs) have also not been left behind by this trend. MFIs have for some time now been perceived by the developing world as a tool to alleviate poverty.

In Uganda, the financial sector is made up of formal and informal institutions. Most of the formal institutions are located in or close to urban areas leaving the informal mostly to rural areas. It is estimated that only $10 \%$ of the rural population and $5 \%$ of the rural poor have access to formal financial services (Nanyonjo and Nsubuga, 2004 cited in Ssewanyana, 2009). The financial services in the rural areas are mainly supported by informal Savings and Credit Cooperative Societies (SACCOs) and a few registered MFIs. Most of these institutions are at a low level of ICT usage compared to some of the internationally recognised financial institutions (Ssewanyana, 2009). Indeed efficient use of ICTs in MFIs can help to cut down the cost of coordination, information processing, and can enable efficient service provision at lower costs. ICT usage in MFIs promotes the dual objective of microfinance, which is sustainability and outreach.

However, the micro-finance scenario in Uganda is changing rapidly. Mainstream banks have started looking seriously at the micro-finance market. As clients repeatedly prove their repayment performance, micro-finance portfolios are becoming a reasonable investment option for those banks seeking to diversify their portfolio, expand their outreach, cater for their social conscience or meet government regulations. Certainly, this means competition for the MFIs. Considering the fact that these established financial institutions have better resources than MFIs, it is important that financial service delivery channels in MFIs become more streamlined, efficient and easy to manage. This is the only way MFIs can remain competitive. To achieve this, MFIs in Uganda need an Enterprise Architecture (EA) that is responsive to their strategic goals. EA is a holistic expression of an organisation's key business, information, application and technology strategies and their impact on business functions and processes. The purpose of EA is to optimise and transform the often fragmented processes, information, application systems, and technologies into an efficient and integrated environment supportive of the execution of business strategy. To help execute business strategy and realise strategic goals, EA defines a desired target state view of an enterprise's processes, information, application systems, and technologies. EA can provide MFIs with an approach to put all the different aspects into perspective and evaluate the trade-offs and solutions in a way that creates ICT assets and optimises the entire enterprise, rather than creating local solutions that become integration and maintenance liabilities. Besides avoiding bad decisions, EA can provide MFIs opportunities to improve the quality of their financial products and line-of-business concerns, improved risk analysis and fraud protection.

In this study, we present a design of a target EA that can enable MFIs in Uganda achieve competitive advantage through the use of ICTs by becoming efficient and 
effective in the provision of financial services to both urban and rural communities. In order to get a clear understanding of the operations of MFIs, Pride Micro-finance Limited (PML) was adopted as a case study. PML is a Micro-finance Deposit-taking Institution (MDI) that provides financial services to that segment of the Ugandan population that is not served or is unable to access financial services through commercial Banks. PML's focus is the micro, small and medium size entrepreneurs the majority of whom are found in the rural areas of Uganda. The study focused on the loans, account opening and deposit-taking sections of the operations department with particular focus on the mission and goals, business processes, information/data, applications, actors, and technological infrastructure.

The study was justified due to challenges that MFIs face, such as high interest rates on loans, limited outreach, high costs of administering small transactions on savings accounts, money transfer and loans to poor people which provide low profit margins (Amin, 2007; Hishigsuren, 2006; Mathison, 2005). With these challenges in place, a lot needs to be done to enable MFIs meet their dual objective of outreach and sustainability. Therefore, this study was one of the ways to tackle some of the problems affecting MFIs in financial service delivery in Uganda.

The designed target EA is expected to enhance efficiency and effectiveness in MFIs in providing financial services especially to rural communities in Uganda. It will also reduce operational costs since it seeks to reduce the amount of paper in the operations of MFIs. It is also expected that the findings of this study will be used by other researchers to carry out further study on how financial service delivery can be improved in MFIs.

\section{Methodology}

The study undertook a qualitative approach to access respondents' experiences from their own perspective. Within this approach, the study adopted a case study design because it allows for a holistic analysis of a case in sufficient breadth and width in order to get insight into the larger cases (Oso \& Onen, 2005). This would offer an indepth understanding of how and why certain phenomena occur in their real life context. The study population comprised operational staff, management, and customers of PML. The operational staff and managers employed were those that had a good understanding of the business goals and mission, key business processes, applications, and technological infrastructure at PML. With regard to the customers, focus was on those customers that had been accessing financial services from PML for at least two years. Some of these were assumed to have good perceptions about the strengths and weaknesses of the financial services offered by PML. Purposive sampling was used to select respondents in a strategic way depending on particular criteria. The technique was also used because it is the most suitable for small populations (Jarvinen, 2004). A small sample of respondents was selected from the target population described above.

Data was collected from both primary and secondary data sources between 11 June and 15 July 2012. Primary data was collected from both the employees and 
customers of PML. Questionnaires and observations were used to collect primary data. The questionnaires were used to collect respondent's perceptions about the strengths and weaknesses of the business services, applications, and information technology infrastructure. The observation method was used to collect information about employees' interaction with customers during financial transactions to determine the challenges faced by both parties. Document review was used to collect secondary data obtained from online journals and PML's business documents in order to determine the nature of data captured.

Questionnaires were the main instruments of data collection. They constituted both open ended and close ended questions and divided into sections according to the information requirements of each architecture domain. Each of the architecture domains focused on a specific business area within PML which included the business, information/data, applications, and technology domains. Self-administered questionnaires are easy to administer, provide quick responses, and the analysis is faster. Respondents were encouraged to explain their answers on specific questions by providing explanations, rationale, and additional context. Direct observation was used to verify information obtained from questionnaires and gather information that could not readily be obtained using the questionnaires. This was very rewarding because the physical visits to PML helped the researchers to get first hand information about the activities involved in the delivery of financial services to its customers. Documentary review was used to capture data that could not readily be obtained using the other data collection instruments.

Colaizzi's (1978) framework for data analysis was used to analyse the data collected. This was done between 20 July and 15 August 2012. The analysis of the answered questionnaires and the business documents obtained from PML was used to describe the challenges faced by both the customers and employees of PML in financial services delivery.

The target EA was designed based on TOGAF (The Open Group Architecture Framework) between 20 August and 25 September 2012. TOGAF is an architecture framework that provides the methods and tools for assisting in the acceptance, production, use, and maintenance of enterprise architectures. TOGAF was used because it supports the development of consistent architectures, reflects the needs of stakeholders, employs best practises, and gives due consideration both to the current requirements and likely future needs of the business. It also provides a platform for adding value and enabling users to build genuinely open systems-based solutions to address their business issues and needs. The other frameworks currently in use today include The Zachman Framework for Enterprise Architecture, The Federal Enterprise Architecture Framework (FEAF), and The Gartner Methodology. TOGAF was preferred because it is the standard framework for Enterprise Architectures widely used by many companies in the world.

To realise the target EA, we first established an architecture effort by establishing the scope, constraints, and goals. We also established the business context which consisted of the key business requirements based on the main findings of the study. 
Secondly, we designed the business architecture where we show how the target architecture realises the key business requirements. Thirdly, part of the data architecture was realised through a conceptual data model which shows how the different data entities relate to each other. Fourthly, the application architecture was designed that describes the structure and behaviour of the major kinds of applications, their key components, their interactions, and their relationships to the core business processes. Lastly, the technology architecture was designed that describes the logical software and hardware capabilities that are required to support the deployment of business, information, and application services within MFIs.

Archimate modelling language was used to model the target EA of PML because it supports the description, analysis, visualisation, and communication of the architecture within and across all domains. Secondly, Archimate is fully aligned with TOGAF. To create the target EA models, Archi and Open ModelSphere design tools were used because they were easily available from the Internet and free.

\section{Findings, Analysis, and Discussion about PML}

\section{Background to Pride Micro-finance Limited}

Based on documents reviewed such as policy manuals and performance reports, PML was founded in 1995 by the government of Uganda to alleviate poverty especially among the rural people. In 2003, PML gained the status of a Micro-finance Deposittaking Institution (MDI). PML is currently a member of the Association of Microfinance Institutions in Uganda (AMFIU). It provides financial services to that segment of the Ugandan population that is not served or unable to access financial services through commercial banks. PML's focus is on the micro, small and medium sized entrepreneurs. The institution also offers money transfer services through Western Union. Their vision is to be a leader in the provision of financial and microfinance services for the social and economic growth of entrepreneurs in Uganda. Their mission is to provide financial services to micro, small, medium and up-scale entrepreneurs in rural and urban areas, through sustainable operations that promote social and economic growth of their customers. PML currently provides deposit and loan products and other services such as money transfers (Pride Microfinance Limited, 2010).

\section{Respondents}

In total, the study surveyed 30 respondents: 8 business managers, 2 IT managers, 10 employees from the operations departments and 10 customers. The business managers included the branch managers, loan supervisors, customer care managers, operations managers and IT managers. PML does not have IT managers at the branch level. The IT managers that the study employed were all from PML headquarters based at Entebbe. As a way of analysing whether financial services delivery at PML meets the expectations of its customers, the study employed 10 customers. In summary, 16 respondents were selected from PML Entebbe Branch while the remaining 14 
respondents were selected from Mbarara branch. PML has about 29 branches country wide. The selection of the two branches - Entebbe road branch and Mbarara branch was based on the nature of clients that they serve. Entebbe road branch is located in the centre of Kampala - the capital city of Uganda; it mainly provides financial services to urbanised customers. Mbarara branch, on the other hand, is located in Mbarara - an upcountry town and mainly serves people in the rural areas.

Out of a total of 30 questionnaires administered to the customers and employees in the two branches of PML, 27 of them were returned and analysed. One of the more common frameworks used to analyse data from qualitative studies is that of Colaizzi (1978). The basic outcome of this method is the description of the meaning of an experience often through identification of useful themes. In this study, Colaizzi's framework for data analysis was used. The answered questionnaires and the business documents obtained from PML were first individually reviewed to extract useful statements. The meaning of each statement was then formulated. Thereafter, the formulated statements were organised into clusters of themes; then, a description of the different themes was carried out. This analysis combined with observations made during a customer's transactions with PML helped in providing a clear understanding of the challenges that both the rural and urban customers of PML face in as far as accessing financial services is concerned. Furthermore, data from these sources also provided a good insight into the challenges faced by PML in providing financial services to its clientele. These challenges are described below.

\section{Current situation of PML}

In order to understand the current situation of PML, questionnaires were analysed qualitatively. Business documents such as loan application forms and account opening forms and observations made helped the researchers to get good insights into the operations of PML with respect to account opening, loan processing, and deposittaking. Below, we elaborate the current situation of PML with specific reference to account opening, loan processing, and deposit-taking.

\section{Current Business Description: Account Opening, Loan Processing, Deposit-Taking}

Although the current account opening process is computerised, it is tedious. The nature of this process demands that each time a prospective customer wishes to open a new account, they must travel to one of the PML branches. There are three different actors in this process: a prospective customer, a customer care officer and a PML branch manager. Each of these actors plays a different role in this process. The basic work-flow of the account opening scenario entails filling the Account opening form by the prospective customer. To fill this form, the prospective customer must submit a photocopy of a valid identity card or letter of introduction from the chairperson of a Local Council where he/she resides. This document is validated by the Customer Care Officer. Once the Customer Care Officer is satisfied with the documentation, the application is forwarded to the Branch Manager who approves the account. Once the account has been approved by the Branch Manager, the Customer Care Officer 
captures the thumb print of the customer using a biometric scanner. The customer is then provided with a temporary signature card.

Loan processing is one of the most important business processes for any MFI. For PML, this important process involves a PML official visiting the customer to confirm his/her place of residence. There are four different actors in this process: a customer, a loans officer, a Branch Loan Committee, and a branch manager. Although each actor plays a different role within the work flow, all of them must participate in order to complete this process. The basic work-flow of loan application and approval scenario includes filling a loan application form by the customer. This is normally done at the branch offices of PML. The Loans Officer then visits the customer to verify both the security to be offered and the purpose for which the loan is required. After visiting the customer, the loans officer prepares a report which he submits to the Credit Committee. The Credit Committee evaluates the loan application and then prepares a submission advising the Branch Manager to either approve or reject the loan request. The submission is normally signed by at least three members of the Credit committee. Once the Branch Manager receives the report from the Credit committee, he/she takes a decision to either accept or reject the loan request. The Loans Officer then notifies the customer of the outcomes of the request. If the loan request is approved and the customer is willing to carry cash, then the Branch Manager organises the money for the customer. However, if the customer is not willing to carry cash, the Branch Manager disburses the loan in form of cheques to be cashed at the customers nearest local bank.

Taking deposits has never been a core business function of MFIs because their focus is to provide development capital to the underprivileged who in most cases do not have money to save. This service was introduced by PML in order to ease the banking of loan instalments by its customers. In fact, one of the requirements to get a loan from PML is to have an active account with PML. There are two actors for this process: the customer and the teller. To deposit money, a customer fills a deposit form that is obtained at the PML branch. The money together with the deposit slip is handed over to the teller. The teller checks the money and then enters the value into the system. Once the money has been entered into the system, the teller enters the deposited amount into the customers Passbook. Customers of PML use their Passbooks to prove to members of their clusters that they have paid their loan instalments.

\section{Current Data Description}

PML collects a lot of data in the course of providing financial services to its customers. This data normally includes customer details such as name, address, biodata, employment status and record, place of residence, location of business if any and any other bank accounts held. Collection of data is done both manually and by use of ICTs. Manually, PML customers are given forms to fill. This normally happens during account opening and loan application processes. The commonly used ICTs in data collection include biometric scanners and photographic cameras. The biometric 
scanners are used to capture the thumb prints whereas the photographic cameras are used to capture the still images of the customers.

Most of the collected data is normally processed and used for decision making, identification of customers and for development of new financial products. The Customer Care officers at different branches of PML are responsible for maintaining the quality of the collected data. PML does not have any specialised person at their branches to help in data management; the task is left to the ICT department. However, PML's ICT department does not have officers at every branch. These officers are stationed only at the regional branch offices and PML headquarters. This means that anything concerning data management must go either to the PML headquarters or regional branch offices.

Storage of collected data at PML is by use of manual files and computer servers. Several servers are used to store the processed data. These servers are located in multiple places. Some are located at the headquarters while others are located at regional offices. Access to stored information is limited to the normal user group. Anybody outside the normal user group can only gain access to the stored data through Customer Care officers. PML does not dispose of any stored data but it instead archives it, especially data that is not required for daily operations. If data is to be archived, the IT department prepares it and then stores it on external hard disks or servers that are specially set aside for this purpose. Once data has been archived, permission to access this data can only be granted by the Head of IT.

\section{Current Application Descriptions: Account opening, Loan processing, Deposit-taking}

Only one application is used in the account opening process. This application not only captures the details of the prospective customer but also helps in the processing of the new account. Information about the status of one's application can only be obtained from the MFI branch where the application was submitted. There is no mechanism put in place to help prospective customers know the status of their account applications other than travelling to the branch where the applications were submitted.

The loan process also makes use of only one application. This application is used to capture the customer details and assess whether the customer is fit to get a loan. A customer who wishes to acquire a loan must travel to an MFI branch and fill a form. There is currently no other mechanism that is being used to capture customer details besides the paper-based system. Loan processing and disbursement also require that the customer travels to an MFI branch. Only one application is used in deposit taking. This application captures the customer deposit details and processes the bank balance.

\section{Current Technology Infrastructure Description}


The current technology infrastructure consists of database servers, application servers, and Internet, all providing different infrastructure services to the application components. Although the current technology architecture has the capability to support online account opening and loan application, it cannot support mobile money transfer.

\section{Challenges faced by PML in financial service delivery}

From the questionnaires analysed and observations made by the researchers, the following challenges were discovered in the operations of PML.

\section{Collection of Information from Customers}

Most of the employees noted that collection of information from customers is one of the biggest challenges that PML is currently facing. Every time information about its customers is required, PML has to send its field staff to the rural areas. This is costly especially if the customers are located in a remote area. In most cases, it is the customers who have to meet this cost. PML has many clients who are spread all over the country. If PML is to move out to collect information from all its clients, one can imagine the technical challenges involved. Conducting millions of small transactions especially in remote areas with very little infrastructure is an operational puzzle that would make any corporate manager unsettled.

Bringing PML to rural villages every week is not a simple thing to fathom. Most of this task falls upon the shoulders of PML field staff. Every day, field staff travels from village to village documenting clients, processing applications, conducting meetings, collecting repayments, disbursing loans, resolving disputes and doing all of the customer centric tasks upon which the entire institution relies. Considering the problem in terms of information flows, there is a lot of data generated in each of these villages every week that needs to be collected in a timely and efficient manner. Every week new customers must be documented, loan applications processed and transactions posted. Moreover, expanding a micro-finance institution's business requires knowledge about prospective customers as well as existing ones. Perhaps even more challenging is the literally thousands of transactions that must be captured and processed every week in a timely manner, so that PML can have an accurate view on its current loans, pinpointing delinquency and potential trouble spots. PML must be vigilant about its loan portfolio and actively follow up on delinquent loans if it is to earn a return on its investment.

There are several other efficiency factors that are important for the growth of an MFI. Two of these include how quickly the loan officer can conduct daily customer interactions, and the number of days it takes to process a new application for credit. This determines the amount of time loan officers have to capture new customers versus dealing with existing ones, and thereby the speed at which the institution can absorb more capital and expand its operations. As micro-finance is a rapidly growing industry with a large untapped market, unpredictable growth is an important thing for MFIs to manage, particularly in competitive markets. 


\section{$\underline{\text { Transferring Money in and out of Rural Areas }}$}

It was noted that a good number of customers of PML are located in rural areas; therefore, PML has to transfer money in and out of the rural areas. PML conducts this in a cash centric and labour-intensive way. Transactions are normally conducted directly between loan officers and clients. Cash payments are collected in the field by a loans officer and returned to the PML's branch office. Loan disbursements are handled similarly. Loans officers travel to the field to disburse the loan directly to the client. If the place of residence of the client is far, the loan officer may ask the customer to come to the branch offices. If there is a nearby bank that will honour cheques for PML customers, the PML Branch Manager disburses loans in form of cheques issued in the name of the recipients. It is the responsibility of the loan recipient to go and cash the cheque at the nearest bank branch. Sometimes bank branches are not accessible nearby, or will not deal with people whom they perceive as poor, uneducated micro-finance customers. In such cases, Loan officers travel to villages with the cash. Due to safety and security issues, PML does not always do this and instead requires clients to go to its branch office usually in groups, also because of security reasons, to collect the loan.

For customers, cash transactions are clearly the most convenient. However, security issues make cash difficult to transport into and out of villages. PML normally gives loans to groups of people as a means of ensuring repayment of the loans. As groups often meet according to a regular schedule, it is easy for a potential thief to predict when a Loans officer might be travelling through an area with a significant amount of cash. Transacting in cash also increases the potential for fraud by loan officers. It is possible for loan officers to under-represent loan repayments. This is one reason that PML cannot offer flexible savings products to their clients. Even if it was allowed by the government, it would be too difficult for the PML to track how much money a loans officer should be bringing back and forth from the office every day. This would leave the door wide open for fraud that could take weeks, if not months to track down.

To meet these challenges, PML depends heavily on local bank branches for handling their cash transactions. In addition to issuing loan disbursements using cheques, PML collects repayments by asking clients to make deposits in specified accounts. The clients bring the processed deposit slip to the group meeting as proof of their payment. PML then transfers these funds out of local accounts into their main institutional accounts. However, in our view, this cannot be taken as a long-term applicable solution; it is a short-term way to shift risks and expenses from PML to customers and banks that have branches close to the rural areas. In Uganda, not many banks have established branches in rural areas. This then leaves the customer with the burden of travelling from the rural areas to the nearest bank or PML branch to conduct transactions. 


\section{Design of the target Enterprise Architecture (EA) of PML}

Below, we present the architecture vision, strategic objectives, and principles of PML that was used to guide the design of the target EA as well as the business requirements that need to be met by the designs.

\section{Architecture vision}

The vision for the target EA is: To enable better information technology decisions that are driven by the business needs of the MFIs in the delivery of financial services.

\section{Strategic objectives and principles}

The design of the target EA of PML was driven by the strategic objectives of PML. These strategic objectives helped to derive the principles that would later guide the design process. The following are the strategic objectives of PML (Pride Microfinance Limited, 2010).

- To increase capital base organically by $20 \%$ and attain a return on investment of $30 \%$ with an aim of transforming into a Commercial Bank.

- To increase customer base by an average of $24 \%$ and active borrowers by $10 \%$ per year.

- To grow quality loan portfolio by $25 \%$ and attain a Portfolio at Risk rate of below $3 \%$.

- $\quad$ To develop a robust IT system at $98 \%$ uptime performance level that supports PML's growth and customer service aspirations.

- To register an $80 \%$ level of efficiency and effectiveness in administrative systems and processes and maintain a cost to income ratio of $75 \%$ and below.

From the above strategic objectives, we were able to formulate seven principles that would guide the design of the target EA of PML. These are outlined below.

1. Investment decisions shall be defined by business requirements as a strategy;

2. Information and information services shall be reliable, accurate, and timely;

3. PML business initiatives and investments must return a business benefit;

4. The integrity and confidentiality of information and data produced and managed by PML must be protected;

5. Capabilities including business processes, information, applications, and technical assets are able to evolve and adapt to a changing environment;

6. Capabilities including business processes, information, applications, and technical assets meet quality service standards for performance and reliability; and

7. Data and information are assets that have value. 


\section{Business requirements (identified needs)}

After analysing the needs, issues and concerns of the various stakeholders, business requirements were identified in the following areas that need to be addressed by the target EA.

1. Transferring money in and out of rural areas. In this regard, customers need to use outlets set up in the rural areas to withdraw and deposit money.

2. Exchange of information with remote clients - the customer and PML need to exchange information in a cost effective manner.

3. Data management and security need to be well streamlined and managed.

4. Registration of new customers should be done online and the processing done at the PML offices.

5. Loan application form can be filled online and the processing is done before the customer travels to the MFI branch. Clients will need to be educated and trained on how to use the online system.

\section{Target enterprise architecture of PML}

The detailed descriptions of the different architecture domains that make up the target EA are described in this section. In terms of PML, the target EA contains models and artefacts that describe the following:

- business capabilities and the business processes used to realise those capabilities(business architecture);

- a data model depicting the data entities used and maintained by these business processes(data architecture);

- $\quad$ applications and their key components used to automate the business processes and maintain the information (applications architecture); and

- $\quad$ technologies used by these applications (technology architecture).

\section{Business Architecture (BA): Account opening; Loan processing; Deposit- taking}

The target BA model for the account opening shown in Figure 1 introduces an online application system to address the challenges associated with the current application process in MFIs. The main aim of the online application system is to avail an online interface to capture the details of prospective customers. Once the applicant keys in the application details, an Application ID is provided by the system. The processing of the application is done internally by the MFI and once the application has been approved, the applicant is notified using the application system. To ensure that somebody else does not gain access to the applicant's approval information, the system only allows one to access such information after entering the Application ID. The applicant goes to the MFI branch only to have the Identity validated and pay the opening balance. 


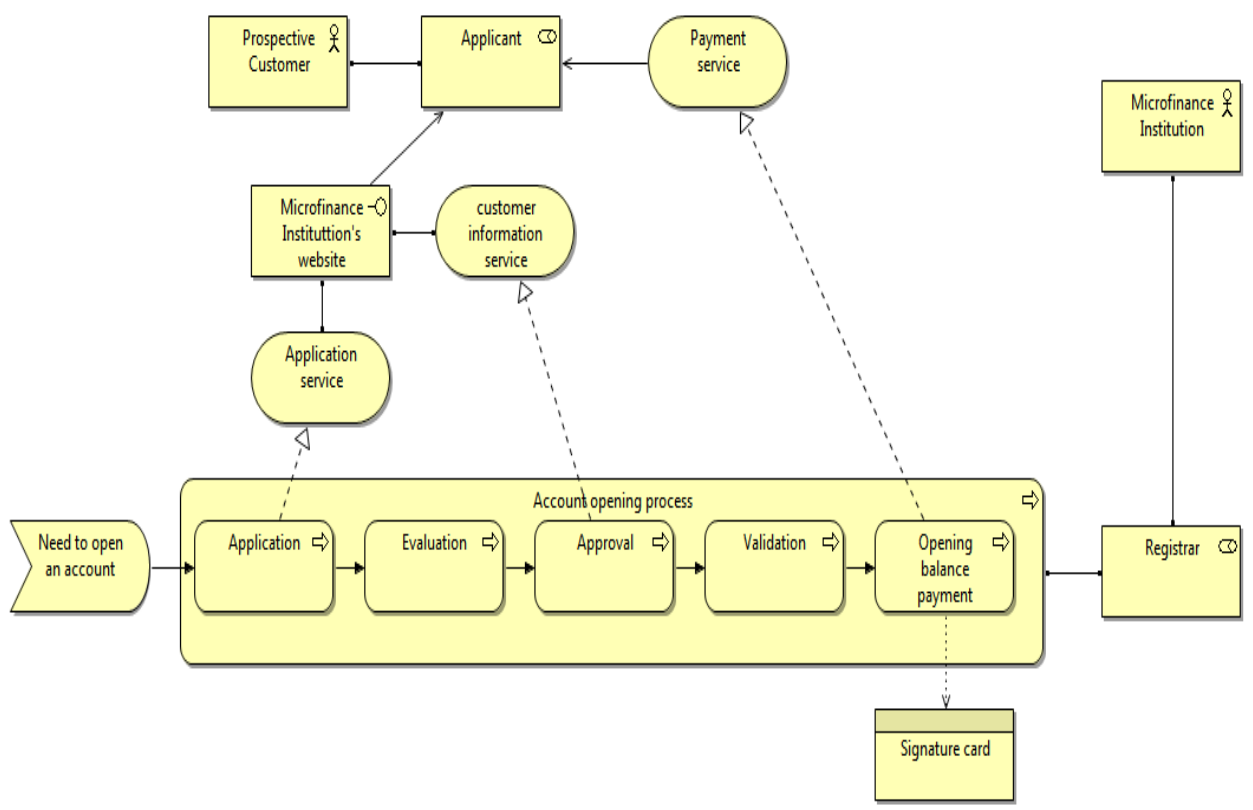

Figure 1: Target Business Model for Account opening

The target loan processing BA model in Figure 2 introduces an online loan application system. The main aim of the online application system is to avail an online interface to capture the customer's loan application details. Once the applicant enters the application details, an Application ID is generated by the system. The application is then assessed basing on the entered information and then the applicant is notified. Notification is also done using the application system. Access to the assessment report is by entering the Application ID. This helps to ensure that only the applicant has access to the evaluation report. If the loan application is successful, the applicant is invited to the MFI branch to have his/her security validated. In addition to overcoming the challenges associated with disbursement of loans especially for customers from remote locations, the target BA introduces a mechanism where the MFI system is connected to the mobile money system. 


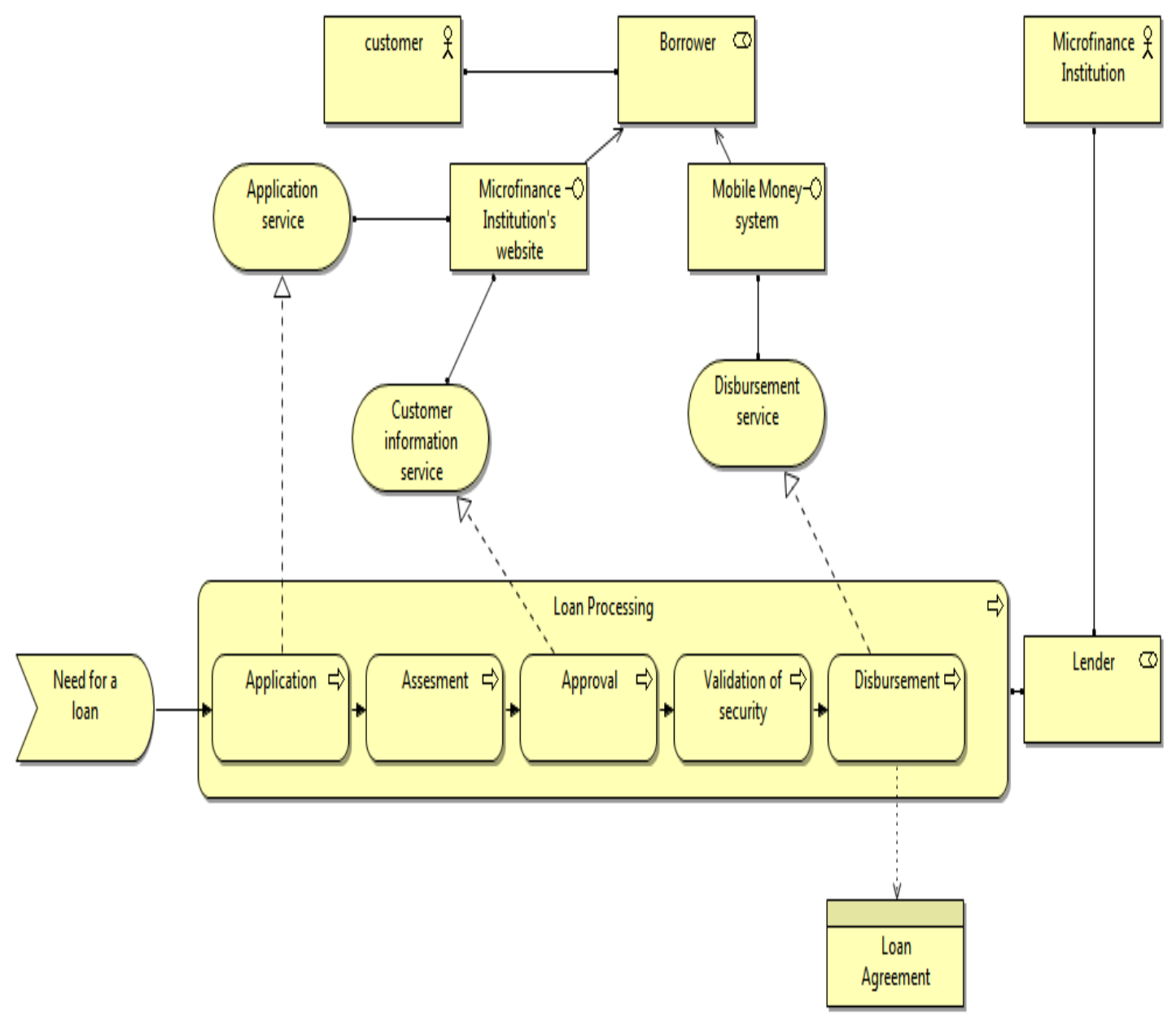

Figure 2: Target Business Model for Loan processing

The target Deposit-Taking BA in Figure 3 introduces a mechanism where a customer can make deposits using the mobile money system as an interface. To be able to make deposits using the mobile money system, both the MFI and the customer must have a mobile money account. When a customer wishes to make a deposit, he/she first deposits the money into his mobile money account and then transfers that money to the mobile money account of the MFI. Once the money has been transferred, the customer receives a message from the bank confirming the transfer. 


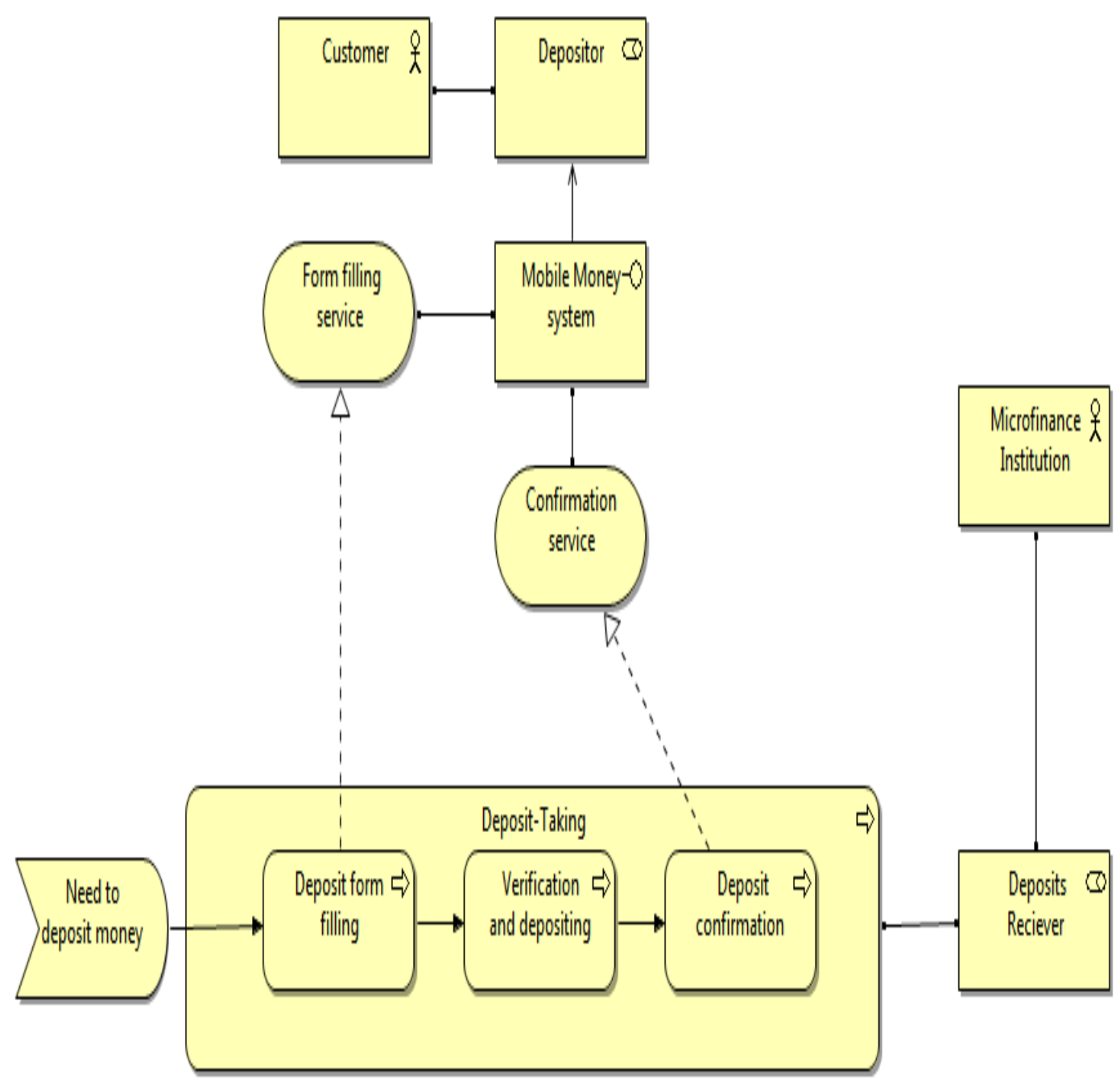

Figure 3: Target Business Model for Deposit-Taking

\section{Data Architecture}

For the data architecture view, a high level conceptual data model is shown in Figure 4. The model details the different data entities from which data are collected. Key data entities in this model include prospective customer, customer, MFI Loan Account, MFI savings Accounts, MFI mobile money account, Customer mobile money account, loan application form, account application form, and MFI Branch. 


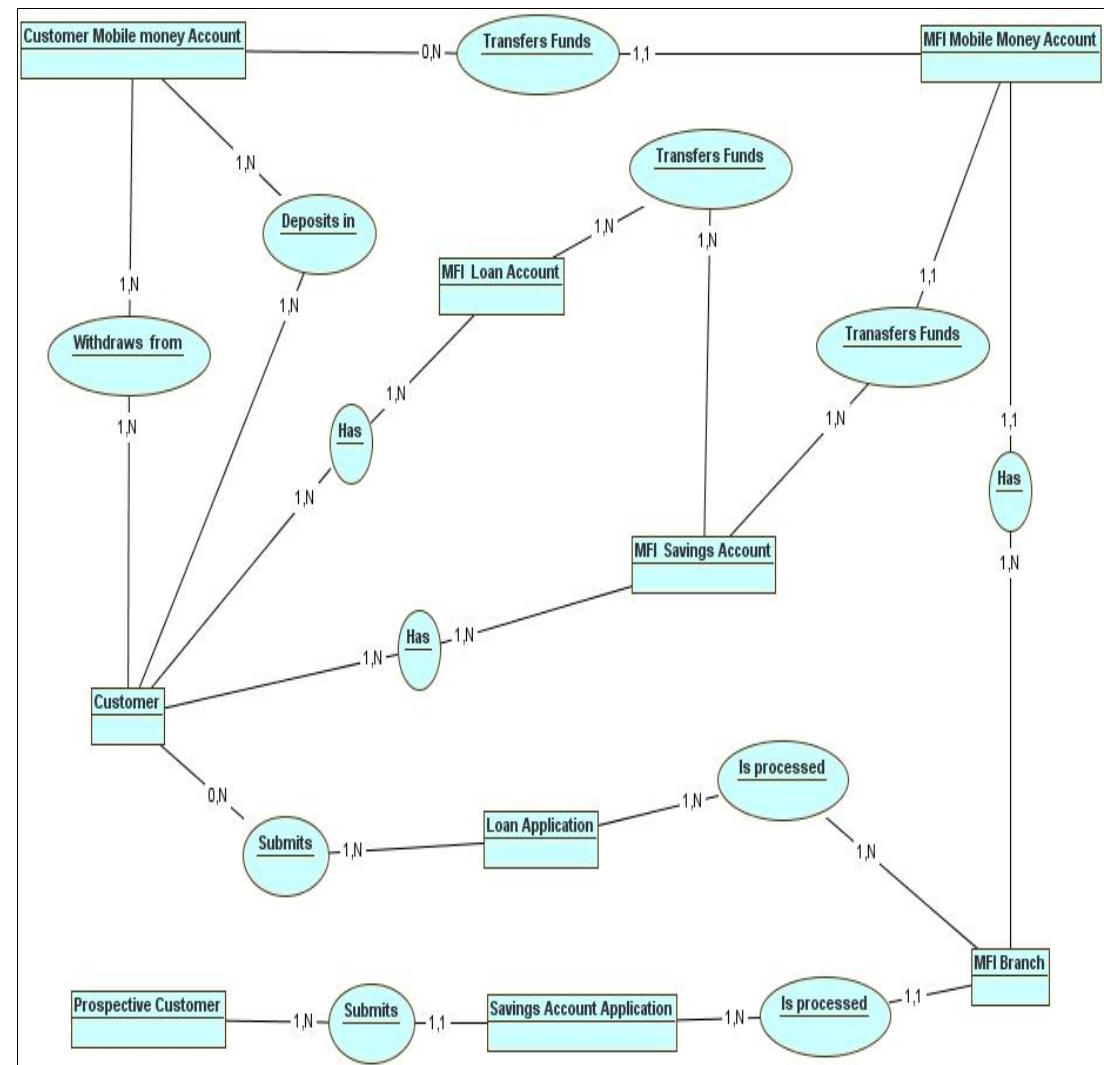

Figure 4: Target Conceptual Data Model

The meaning of the entities is shown below.

- Prospective Customer: details of people who have submitted applications for savings accounts.

- Customer: details of people who benefit from financial services of the MFI.

- MFI Loan Account: details of customers with loans.

- MFI savings Account: details of customers holding savings accounts.

- Loan application: details of loan applications.

- Account application: details of savings account applications.

- MFI Branch: details of MFI branches.

\section{Application Architecture (AA): account opening, loan processing, and deposit-taking}

The target AA model for the account opening process shown in Figure 5 has four application components realising six application services. Four of the application services are used by business processes in the business layer while the remaining two services are used by application components to realise application services. The application services that are used by application components include; the account 
approval service and the customer information services. The account approval service is used by the Customer Relationship Management application component to realise the customer administration service while the customer information service is used by the financial application component to realise the cash deposit service. In order to realise the new accounts administration service, the new accounts application component accesses the account application forms.

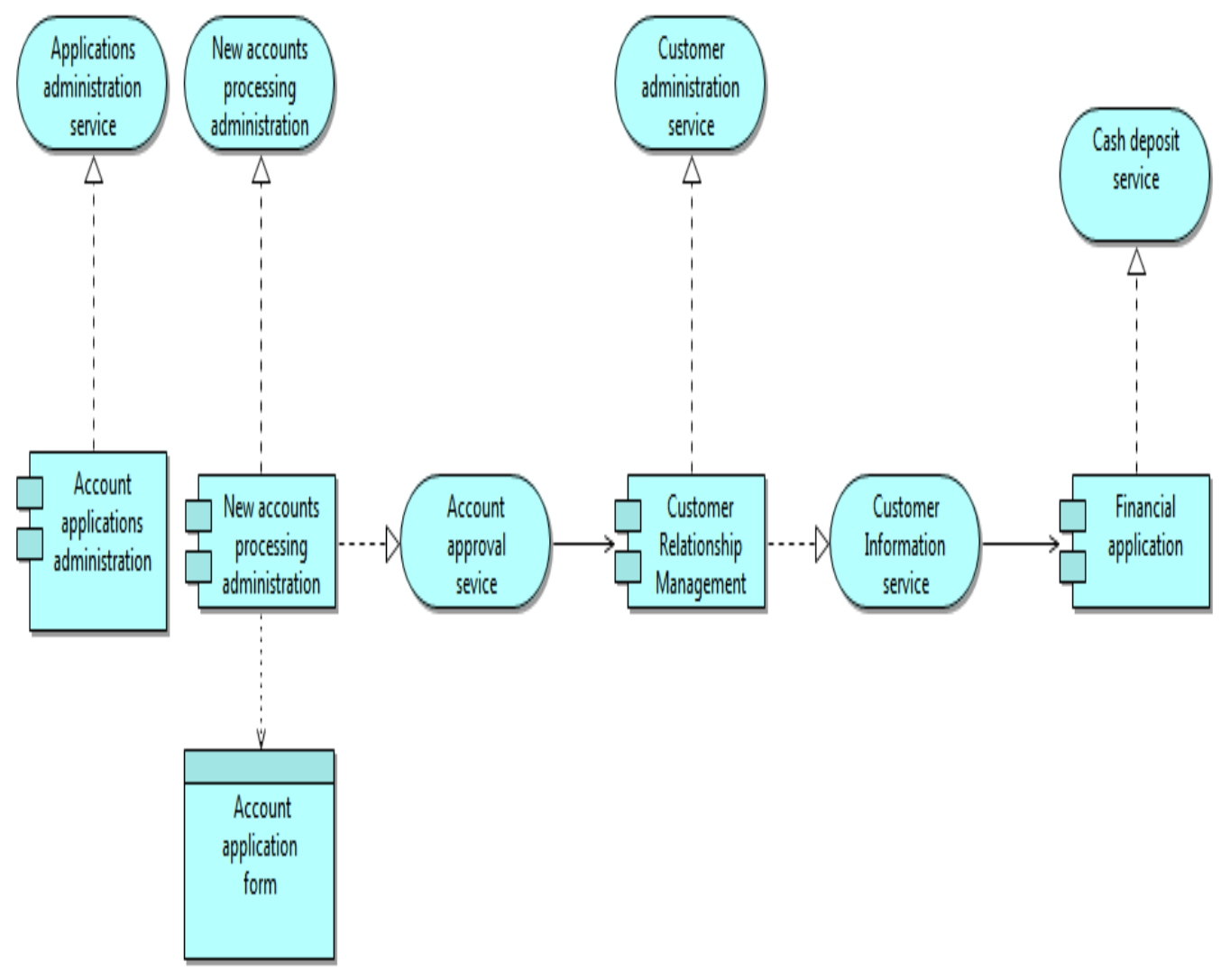

Figure 5: Target Application Model for Account opening

The target AA model for the loan process shown in Figure 6 has six application components realising at least one application service. Five of the application components reside within the MFI system while one is external. The mobile money application component that resides outside the MFI system is linked to the MFI system through a mobile money interface. This application realises the money transfer service which is assigned to the mobile money application interface. The money transfer service is used by the MFI financial application to realise the loan transfer service. To realise the loan processing administration service, the loan administration application components accesses the application form. 

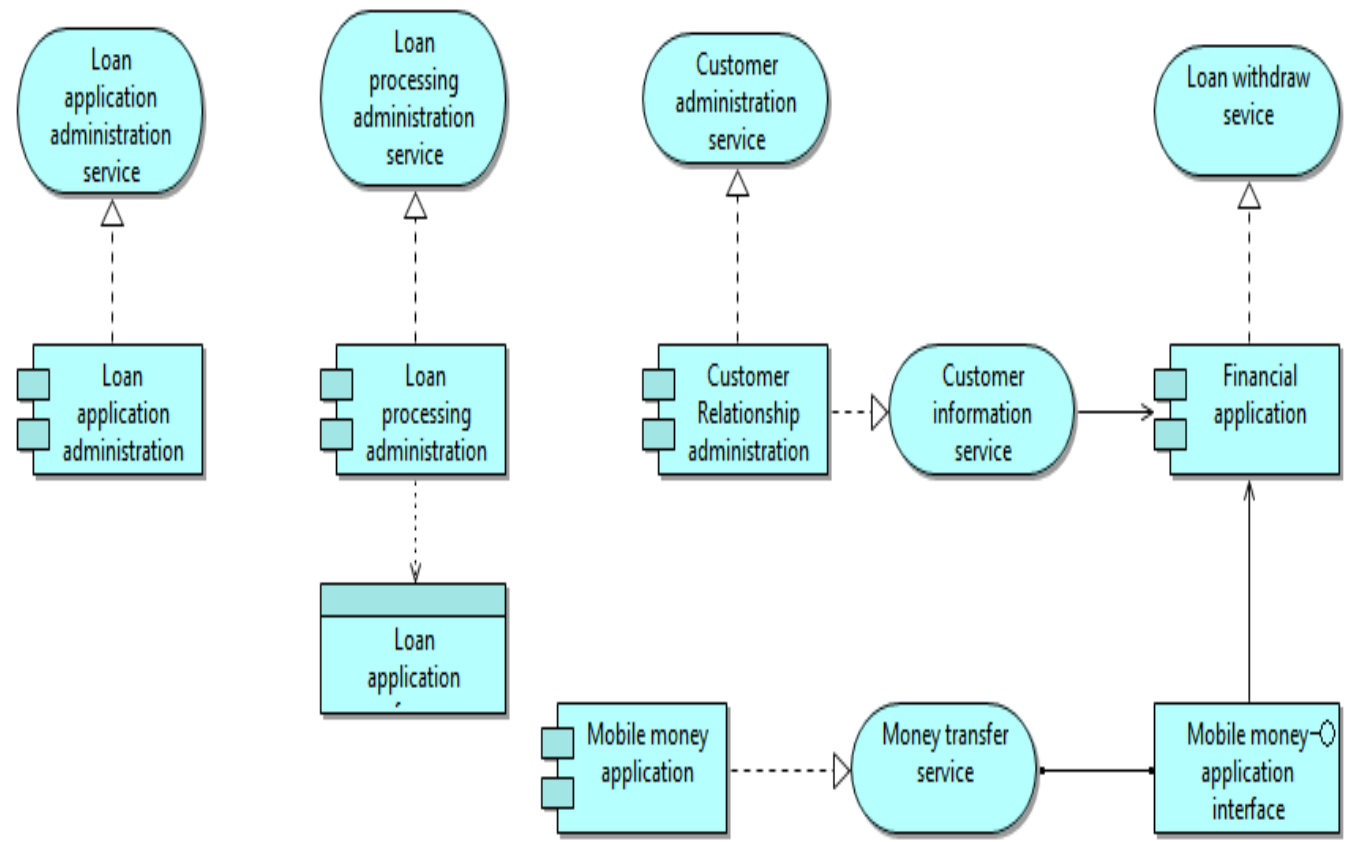

Figure 6: Target Application Model for Loan Processing

The Target Application model for Deposit-taking process has four application components. Three of the application components are internal while one is external. Each of the application components realises at least one application service. As illustrated in Figure 7, some of the application services are used by other application services to realise application services for the business processes. Like the loan process, the mobile money application is external to the MFI and is linked to the MFIs application component through a mobile money application interface. The mobile money application component realises the money transfer service that is used by the financial application to realise the cash deposit service. 


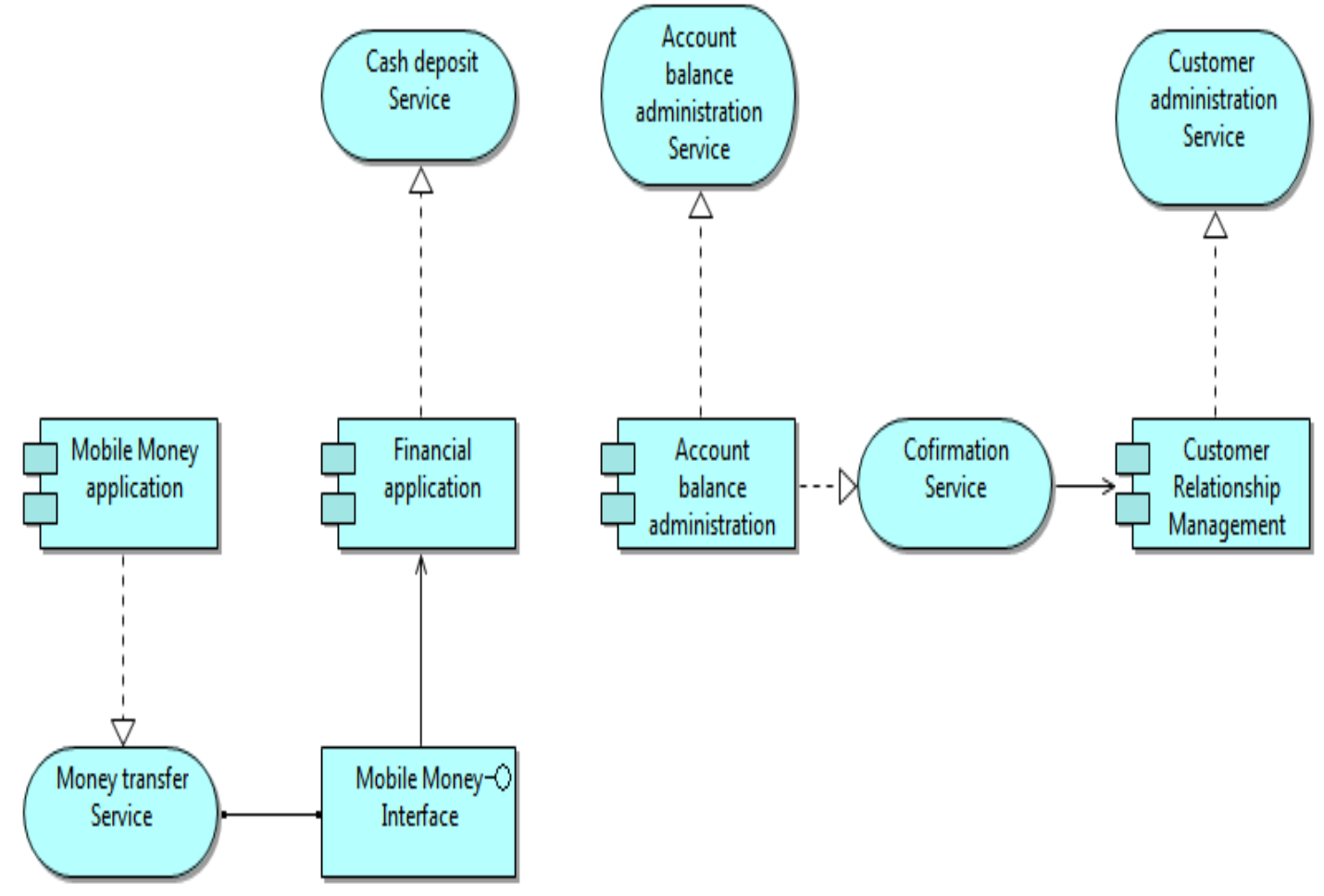

Figure 7: Target Application Model for Deposit- Taking

\section{Technology Architecture (TA)}

The target TA shown in Figure 8 introduces the mobile money application server, the messaging, and database server to support mobile money transfer. The servers are linked to the MFI system via the Internet. These two servers realise services that are used by the mobile money application. These include messaging service, database access service, etc. 


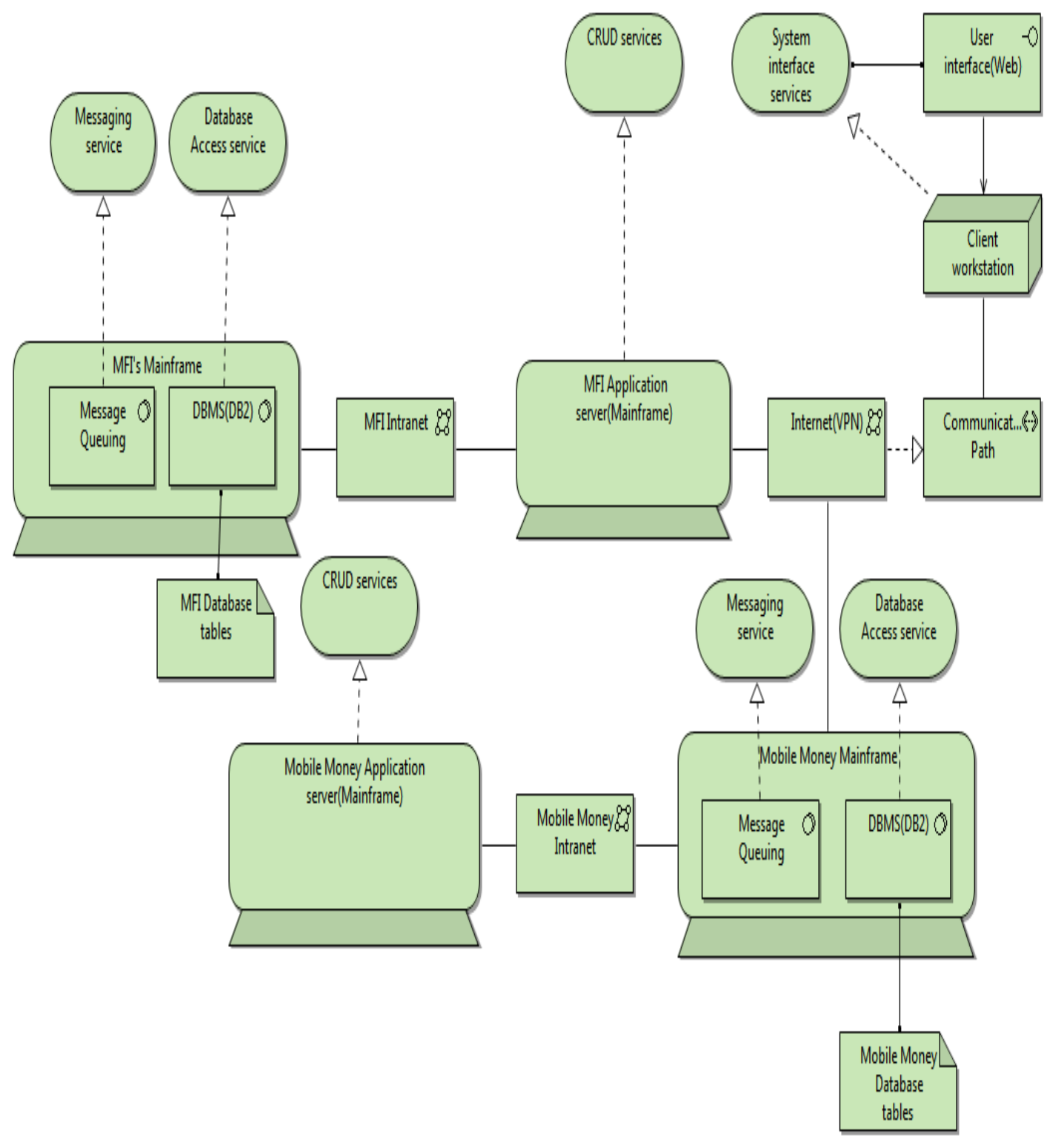

Figure 8: Target Technology Architecture Model

With the above designed target EA for PML, we feel that the main objective of this study was achieved because the decision makers and other stakeholders in PML and all other MFIs in Uganda stand to enjoy the benefits of the architecture if they embrace, implement, and use the designed target EA. Briefly, these benefits include improved outreach to customers; alignment of ICTs with the mission, goals and objectives of the MFIs; lowering of operational costs; improvement in reliability and performance of their systems; etc. 


\section{Conclusion}

The goal of this study was to design an EA that can enable MFIs in Uganda achieve competitive advantage through the use of ICTs. Much focus was put on analysing the financial service delivery channels at PML and how ICTs support these channels. Key business processes were analysed and these included account opening, loan processing and deposit-taking. From the analysis of these financial service delivery channels, it was discovered that both PML and its customers face a challenge in transferring money in and out of rural areas. Given the fact that both transport and IT infrastructure in most of the rural areas of Uganda is less developed, PML spends a lot of money to take loan money to its customers in the rural areas. Similarly, customers have to travel long distances to deposit money and this costs them a great deal both in terms of money and time. The other challenge that was highlighted by many of the respondents was the exchange of information. Each time information about customers is required, PML staff must travel to where the customers are located. Similarly, when a client wishes to access any information, he/she has to travel to a PML branch.

Having analysed these challenges, two conclusions were arrived at: MFIs in Uganda must dare to undertake a radical change and discard old ways of doing business that have proven to be costly and inefficient. To do this, MFIs need to establish an EA that does not require customers to travel to an MFI branch in order to access money, deposit money or exchange information. A target EA that takes advantage of the telecommunication infrastructure in Uganda was designed. This architecture makes it possible for MFIs to reach out to more customers without necessarily having to rely on the brick and mortar infrastructure. Customers can be able to transfer money and exchange information without having to visit an MFI branch. Although capital investments are required to implement this architecture, those investments are only challenging during the initial installation, with much lower costs for adding individual access points.

However, it should be noted that implementation and use of the designed EA brings about data migration, data governance, and information security management challenges. Having an EA in place may not be enough to solve all the challenges that MFIs are currently facing. There is need to support the EA effort with management solutions.

\section{References}

Amin, N., 2007. Enabling the expansion of microfinance using information and communication technologies. IGI Publishing. [Online] Available from: http://new.igiglobal.com/Gateway/DisplayDocbook.aspx?theID=19872\&IsPdf=1 [Accessed 28 September 2011].

Colaizzi, P.F., 1978. Psychological research as the phenomenologist views it. In: Existential-Phenomenological Alternatives for Psychology, R.S. Valle \& M. King (eds.) Oxford University Press, 1978, p.6 
Hishigsuren, G., 2006. Information and communication technology and microfinance: Options for Mongolia, ADB Institute Discussion Paper No. 42. [Online] Available from:

http://www.adbi.org/files/2006.02.dp42.ict.microfinance.mongolia.pdf[Accessed 26 April 2011].

Jarvinen, P., 2004. Research question guiding selection of an appropriate research method. University of Tampere, Series of Publications D-Net publications. [Online] Available from: http://www.cs.uta.fi/reports/dsarja/D-2004-5.pdf [Accessed 21 February 2012].

Mathison, S. (Ed). 2005. Electronic banking with the poor: Increasing the outreach and sustainability of microfinance through ICT innovation. The Foundation for Development Cooperation. [Online] Available from: http://www.fdc.org.au/Electronic\%20Banking\%20with\%20the\%20Poor/EBWTP $\% 20$ Full\%20Document.pdf [Accessed 4 May 2008]

Mulira, H., 2006. The potential and feasibility for community-driven ICT networks in Uganda. [Online] Available from: http://www.wougnet.org/ICTpolicy/ug/docs/cinug.html [Accessed 15 September 2011]

Oso, W. Y. \& Onen, D., 2005. A general guide to writing research proposal and report: A handbook for beginning researchers. Kisumu: Options Printers and Publishers.

Pride Microfinance Limited., 2010. Annual Report. [Online] Available from: http://www.pridemicrofinance.co.ug/images/downloads/PML\%202010\%20Annua 1\%20Report.pdf [Accessed 24 May 2011]

Ssewanyana, J., 2009. ICT usage in microfinance institutions in Uganda. The African Journal of Information Systems 1(3) 5-28

Weill, P. \& Ross, J.W., 2006. Enterprise architecture as strategy: Creating a foundation for execution. Harvard Business School. [Online] Available from: http://cisr.mit.edu/research/research-overview/classic-topics/enterprisearchitecture [Accessed 8 May 2011]

\section{Authors' Biography}

Wamema Joseph is a member of the National Task force for the Government of Uganda Enterprise Architecture Project and a part-time Lecturer at Uganda Martyrs University where he teaches Enterprise Architecture. His research interests focus on Enterprise Architecture creation and health informatics.

Joseph Othieno is an Information Technology consultant and Lecturer at the University of Kisubi. He has specialised in modelling enterprises, data, and applications. His research interests focus on analysing business organisations and innovative use of ICTs in adding value to organisations. 